\title{
ESTUDO DAS COMUNIDADES DISCURSIVAS FORMADAS PELA INTERDISCIPLINARIDADE ENTRE AS ÁREAS DE CIÊNCIA DA INFORMA- ÇÃO E ANÁLISE DO DISCURSO
}

\author{
Study of discursive communities formed by interdisciplinarity between Information Science and Discourse Analysis
} areas

\section{Renata Cristina Gutierres Castanha (1), Larissa de Mello Lima (2)}

(1) Unesp, Av. Hygino Muzzi Filho, regutierres@gmail.com. (1), larissalima.unesp@gmail.com (2)

\begin{abstract}
Resumo
Este estudo objetiva avaliar a Análise do Discurso nos estudos em Ciência da Informação no Brasil, sob a perspectiva da análise bibliométrica de suas comunidades discursivas, em que se encontram os pesquisadores brasileiros expoentes que tratam da temática e seus referentes teóricos. Mais especificamente, busca analisar os indicadores bibliométricos de citação e cocitação, a fim de identificar e analisar seus referentes teóricos, entendendo as estruturas em que se articulam pesquisadores e temática referente à Ciência da Informação no Brasil. Para tanto, realizou-se uma busca na base BRAPCI em novembro de 2015 com as expressões: análise do discurso (sem aspas), "análise do discurso" e "discourse analysis", conjuntamente com "Foucault", a fim de se recuperar todos os artigos referentes à matriz francesa do discurso. A análise consistiu instrumento essencial para o entendimento mais aprofundado do comportamento científico das comunidades discursivas que abordam a escola francesa da Análise do Discurso nos estudos da Ciência da Informação no Brasil.
\end{abstract}

Palavras-chave: Análise do discurso de Matriz Francesa; Análise Bibliométrica; Análise de citação; Análise de cocitação.

\section{Introdução}

A característica transdisciplinar da Ciência da Informação (CI) é constituída por áreas inter-relacionadas que possibilitam a análise e estabelecimento de práticas para a informação, sob uma perspectiva múltipla (Silva e Baptista, 2015).

Tal como as Ciências Humanas e Sociais, a CI divide com a Análise do Discurso (AD) objetos, questões e perspectivas, e tem se valido de suas propostas teórica e metodológica, uma vez que a AD possibilita uma visão ampla de 'texto', a qual converge para uma melhor compreensão dos objetos informacionais (Freitas, 2010).

A AD fundada e praticada por Michel Foucault e seus discípulos é considerada um importante método de

\begin{abstract}
The aim of this paper is to evaluate the Discourse Analysis in studies of Information Science in Brazil, from the perspective of the bibliometric analysis of its discursive, in which we can find the exponent Brazilian researchers who deal with this topic and theoretical influences. More specifically, it seeks to analyze the bibliometric indicators of citation and cocitation in order to identify and analyze the most productive authors, scientific collaboration of authors, institutions and journals that address this issue, as well as to reveal and analyze their theoretical influences, understanding the structures in which researchers and topics work in Information Science. A search was conducted on the BRAPCI database in November 2015 including the terms discourse analysis (without quotation marks), "discourse analysis" and "discourse analysis," together with "Foucault," in order to retrieve all articles referring to the French School of discourse analysis. The results and analysis of these indicators consist on an essential tool for understanding the behavior of scientific discourse communities that address the French School of discourse analysis in studies of Information Science in Brazil.
\end{abstract}

Keywords: French School of Discourse Analysis; Bibliometric analysis; Citation analysis; Co-citation analysis.

pesquisa referente à CI no Brasil. Caracterizado como um método multidisciplinar, fornece uma contextualização do objeto em estudo, uma das principais vantagens da pesquisa qualitativa.

A AD assume o próprio discurso como objeto de análise e consiste no estudo da maneira pela qual um objeto ou ideia, quaisquer que sejam, são assumidos por instituições e/ou posiçõos epistemológicas, e da maneira pela qual tais instituições/posições os tratam. A AD estuda a maneira pela qual os objetos ou ideias são falados, e não apenas a fala em si (Finlay, 1987; Frohmann, 1994).

Isto posto, esta pesquisa tem como objetivo analisar a AD nos estudos da CI, no Brasil, por meio da análise de seus indicadores bibliométricos de citação e cocitação, visando analisar as comunidades discursivas onde 
se encontram os pesquisadores expoentes responsáveis pela disseminação científica da temática no Brasil.

Este trabalho se justifica em razão da pouca existência de estudos que trabalhem na interseccionalidade temática entre bibliometria e AD (Castanha, Lima e Martínez-Ávilla, 2017; Lima, Moraes e Martínez-Ávilla, 2015), uma vez que esta é comumente utilizada nos estudos da CI como método de pesquisa e não como objeto, como aqui se faz.

\section{Fundamentação teórica do objeto de estudo: Análise do Discurso de Matriz Francesa}

Irrompido no cenário da intelectualidade francesa, a conjuntura intelectual do surgimento da $\mathrm{AD}$ fundamenta-se sob a égide do estruturalismo dos anos 60, e caracteriza-se por suas críticas às fortes tendências em destaque no campo, como o estruturalismo, então dominante nos estudos de linguagem, articulando-se em torno de uma reflexão sobre a escritura, a linguística, o marxismo e a psicanálise (Maingueneau, 1997).

É observado que essa conjuntura baseia a escola francesa de $\mathrm{AD}$, uma vez que não existe uma forma singular de realizá-la. O fazer discursivo parte do interesse de estudiosos na linguagem de maneira particular com base nas diversas formas de significar.

Nesse sentido, Orlandi (2003, p.02) ressalta que:

[...]a análise do discurso não trabalha com a língua enquanto um sistema abstrato, mas com a língua no mundo, com as maneiras de significar, com homens falando, considerando a produção de sentidos enquanto parte de suas vidas, seja enquanto sujeitos, seja enquanto membros de uma determinada forma de sociedade.

Entende-se que a $\mathrm{AD}$ francesa é constituída por uma espécie de tríade basilar: ideologia, enunciado e sujeito. Entende-se ideologia como a materialização do discurso, representando a relação imaginária dos indivíduos com suas condições reais de existência (Althusser, 1985).

Foucault (1969) define enunciado como uma função de existência atravessando domínio de estruturas possíveis, há de se compreender o enunciado na estreiteza e singularidade de sua situação; de determinar as condições de sua existência, de fixar seus limites da forma mais justa, de estabelecer suas correlações com outros enunciados a que pode estar ligado, de mostrar que exclui outras formas de enunciação.

Em sua primeira grande obra "História da loucura", Foucault estuda como o conceito de loucura foi formulado e transformado por diferentes discursos em diferentes momentos históricos para assim revelar tal conceito não como uma categoria fixa, estável e inata, mas como o produto de diferentes poderes e estratégias de controle.
Deste modo, revelam-se os discursos e práticas discursivas que fizeram perceber a loucura como uma mostra de sabedoria e de proximidade a Deus, como algo desejável, durante o renascimento; para transformá-la em um mau exemplo, similar à ociosidade, sendo os loucos encerrados junto a pobres e criminosos durante os séculos XVII e XVIII; durante o século XIX, os loucos já eram distintos dos pobres e dos criminosos, mas não existia uma separação, sem dúvida, entre a parte psicológica e a parte física, pois os loucos eram encerrados em hospitais e tentavam "curá-los" com tratamentos físicos como duchas frias, etc. Elementos chave nos trabalhos de Foucault são as análises dos discursos médicos e disciplinares. Por exemplo, em "Vigiar e punir", Foucault analisa o nascimento dos conceitos modernos de crimes e castigos, descrevendo como os tipos de vigilância e de castigo foram transformados. Entender estas mudanças é entender sobre o sujeito ideológico.

Dentro da $\mathrm{AD}$, o sujeito é essencialmente ideológico e histórico, pois está inserido em determinado espaço e tempo. Com isso, o sujeito posiciona seu discurso em relação aos discursos do outro, uma vez que está socialmente situado. Para Foucault (1969), o sujeito é negado pela sua condição de alienação face ao texto. Eliminada a alienação, o sujeito poderia ser também sujeito de seu discurso, mas esta tarefa não caberia aos linguistas (Mazière, 2007).

No que tange ao fato do sujeito ter a ilusão de ser fonte de seu discurso é possível fazer um paralelo com discurso científico. O discurso científico é mais fechado, finalizado em si, na medida, em que o enunciador leva em conta um viés para se comunicar com o enunciatário que nesse caso são os pares da comunidade científica (Guimarães, 2001).

Ao descrever o processo de formação do discurso científico, é ressaltado o quanto este, enquanto gênero secundário, é complexo por ser formado e atestado pelos gêneros primários. Acredita-se que aconteça um fenômeno de engessamento na medida em que a camada da comunicação científica segue regras e padrões argumentativos.

Acredita-se ser importante retomar brevemente o contexto histórico pelo qual a França passava para contextualizar os mecanismos que tornaram possível dar importância para os estudos centrados no sujeito da linguagem e, por conseguinte, discurso. Michel Pêcheux, filósofo de formação, começa a realizar uma forte ligação entre a Filosofia e as Ciências Sociais a partir de uma série de estudos centrados na língua (Henry, 1997).

Tal perspectiva se liga com o movimento que começa a irromper na França de negação ao estruturalismo em meados da década de 1960 . Buscava combater o excesso de formalismo e padronização dos elementos da 
linguagem tratados, por influência dos postulados de Saussure, de maneira estrutural.

Saussure (1973) afirma que língua e fala são diferentes, possuindo relação de oposição. Para Saussure, a língua é o conjunto de signos estruturados, o todo, que uma comunidade utiliza para se comunicar, ou seja, é algo coletivo e social. Já a fala, o autor supracitado denomina como algo individual, particular; é a maneira como as pessoas usam a língua. Embora diferentes, elas se completam, são dependentes uma da outra. A língua, para que possa existir, se estabelecer, precisa de falantes.

Desta maneira, a fala também precisa de um modo para existir, um código, uma ferramenta. Saussure fez seu estudo sobre a língua, pois, segundo ele, era propícia para aprofundamento naquele momento, deixando a fala de lado (Saussure, 1973).

Ao mesmo tempo em que deixou em segundo plano a fala, Saussure deixa aberto um campo de estudo rico e até então sem aprofundamento teórico. Ao serem interligados estes fatores listados acima; o excesso de formalismo linguístico somado ao sujeito que conduz a fala sendo deixado em segundo plano, Pêcheux e seus seguidores criam a Análise do Discurso Francesa.

O marco inicial da corrente teórica foi fixado no lançamento paralelo em 1969 da obra "Análise Automática do Discurso" de Michel Pêcheux e da Revista Langages criada por Jean Dubois (Gregolin, 1996; Maingueneau, 1997).

Torna-se legítimo afirmar que eles possuíam um solo fértil para germinar teorias centradas no sujeito até então esquecido. Ele retoma, por exemplo, elementos da teoria do inconsciente coletivo de Lacan para dar conta de falar sobre o papel desempenhado pelo sujeito nos discursos.

Além disso, são colocados em primeiro plano a questão da ideologia, ele afirma que "a ciência é antes de tudo a ideologia com a qual rompe". Para falar de ideologia ele retoma Louis Althusser, de quem foi aluno e a encara enquanto o que "interpela os indivíduos enquanto sujeitos" (Althusser, 1998), sendo reflexo de uma representação entre a realidade e o sujeito. Seu percurso teórico e metodológico na AD Francesa é sustentado na pirâmide que busca articular o materialismo histórico com a teoria da ideologia, a linguística focando nos processos de enunciação, e a teoria do discurso que coloca em centro a teoria de determinação histórica dos processos semânticos. (Orlandi, 2003)

Nota-se a variedade de abordagens e tipos de AD através da caracterização acerca do objeto discursivo. Isto significa que não existe um modo homogêneo de realizar a análise do discurso, em consonância com a atitude de Foucault em não prescrever um método efetivo.
No entanto, é possível estabelecer algumas balizas que norteiam a perspectiva da análise, ou seja, a perspectiva de materialidade do enunciado sinalizada por Pêcheux, que desemboca na multiplicidade de sentido enquanto uma série de vozes que se confrontam e refletem formações ideológicas plurais.

No caminho contrário às considerações de Foucault, Michel Pêcheux traz a perspectiva linguística como parte fundamental da análise discursiva.

\subsection{Análise do Discurso no Brasil}

Para falar sobre a escola brasileira de AD é necessário percorrer os desdobramentos teóricos da obra de Michel Pêcheux no território brasileiro que devido as suas características históricas, desenvolveu-se de maneira diferente daquele presente no território francês. Devido ao percurso da AD no Brasil, é possível dizer que ainda se fala muito em Pêcheux.

A sua introdução no Brasil sofreu grande influência do regime militar, em 1964 até meados da década de 1980. Costuma-se dizer que, no final dos anos 70 e no início dos anos 80, a análise do discurso foi instaurada no Brasil - mais especificamente na UNICAMP -, onde a professora Eni Pulcinelli Orlandi ministrava os primeiros cursos devido ao enfraquecimento pelo qual passava a ditadura militar nesse período. Ela pondera a respeito da análise do discurso no Brasil

Análise de discurso institucionaliza-se amplamente - não sem algumas resistências, alguns antagonismos $-\mathrm{e}$, com sua produção e alcance teórico, configura-se como uma disciplina de solo fértil, com muitas consequências tanto para a teoria como para a prática do saber linguístico. (Orlandi, 2003, p. 14)

O principal ponto é que, diferente do que aconteceu na França, acabaram por separar a análise dos textos, uma relacionada aos textos escritos e outra preocupada com a oralidade. No Brasil, a análise do discurso manteve o interesse em ambos os tipos de produções, dando uma sustentação diferente ao método e ao uso da mesma.

Conclui-se, assim, a fundamentação teórica do objeto e passa-se agora para o percurso metodológico da pesquisa.

\section{Percurso Metodológico}

Com o objetivo de analisar sob a perspectiva métrica a AD nos estudos da CI, optou-se por realizar uma análise quali-quantitativa dos artigos recuperados a partir dos indicadores bibliométricos de citação e cocitação; somado a isto, esta pesquisa caracteriza-se também como descritiva e documental, visando analisar as comunidades discursivas em que se encontram os pesquisadores expoentes responsáveis pela disseminação científica da temática no Brasil.

Entende-se que o conjunto de referências dos trabalhos científicos pode ser analisado como reflexo de uma 
comunidade discursiva. Seu estudo baseia-se em análises tanto das frequências de citações quanto de cocitações, quer sejam de autores ou documentos possibilitando a visualização do comportamento científico. Nesse sentido, a visualização permite a transformação de conceitos e fenômenos em imagens intelectivas perceptíveis, como também a apreensão de determinados dados e de algumas relações e das estruturas subjacentes que não estão explícitas (Grácio e Oliveira, 2013).

Tem-se uma citação como um indicador de comunicação científica de uma determinada área de estudo, o qual permite a identificação de grupos de cientistas e suas publicações, com a finalidade de evidenciar os pesquisadores de maior impacto da área, assinalando seus paradigmas, procedimentos metodológicos, e também os pesquisadores de elite, aqueles responsáveis pela construção do conhecimento novo na área.

Desse modo, a análise de citação mapeia a comunicação científica e contribui para o entendimento de uma comunidade científica ao identificar os pesquisadores com maior impacto na área e dar visibilidade às referências teóricas que a sustentam, bem como seus conceitos, objetos e métodos, ao contribuir para a construção da rede de relações, e explicitar a comunicação e o relacionamento entre os pesquisadores (Vanz e Caregnato, 2003; Grácio e Oliveira, 2013).

O estudo de co-citações deriva da análise de citações, e trata da frequência com que dois autores ou documentos são citados de forma conjunta na produção científica de uma determinada área do conhecimento. Para Miguel, Moya-Anegón e Herreno-Solana (2008), a análise de cocitação produz representações válidas da estrutura intelectual de um domínio científico.

Para Grácio e Oliveira (2013), a análise de co-citações tem como premissa fundamental que quando dois ou mais documentos, autores ou periódicos são citados juntos, em um terceiro trabalho posterior, existe, pelo menos na perspectiva do autor citante, uma similaridade de assunto entre os citados, e que quanto maior a frequência de cocitação, mais próxima a relação entre os mesmos.

Portanto, autores citados juntos podem apresentar, pelo menos na perspectiva dos autores citantes, similaridade, complementaridade, sobreposição ou mesmo contraposição de ideias. Para Small (2004, p. 71), quando os cientistas concordam quanto ao que constitui a literatura relevante, incluindo o que é significante naquela literatura, eles estão de fato definindo as estruturas de suas comunidades, e ainda, "a estrutura da ciência é gerada por padrões de co-reconhecimento" e "[...] quando documentos são co-citados, autores citantes estão atribuindo co-reconhecimento bem como criando uma associação de significados".
Isto justificado, tem-se que o foco desta análise parte do investigador para o universo da temática, uma vez que foram analisados, individualmente, seus pesquisadores expoentes e referentes teóricos.

Em um primeiro momento, depois de escolhido o objeto de pesquisa, buscou-se na base BRAPCI (Base de Dados Referenciais de Artigos de Periódicos em Ciência da Informação) por artigos referentes à temática em questão. Optou-se pela BRAPCI uma vez que essa base de dados é responsável por reunir em repositório toda a literatura referente à CI no Brasil e por sua importância em âmbito nacional (1).

A busca foi realizada utilizando as seguintes expressões: análise do discurso (sem aspas), "análise do discurso" e "discourse analysis", conjuntamente com "Foucault", a fim de se recuperar artigos que abordassem a matriz francesa do discurso nos discursos da CI no Brasil. Entende-se que a matriz Francesa passa por diversas fases e autores diversos, mas nesse trabalho optou-se por entender a importância de Michel Foucault para esta corrente, justificando assim a escolha de combinação para a busca.

Optou-se por não realizar um recorte temporal uma vez que poucos artigos foram recuperados no total, e a pretensão seria analisar o objeto de maneira sincrônica dentro dos periódicos desta base de dados, que abrange o período desde 1972-atual.

Foram recuperados 24 artigos, os quais passaram, posteriormente, por uma análise básica de conteúdo a fim de visualizar seu encaixe na temática e objetivos propostos e, depois de retiradas as duplicações, considerou-se como corpus da pesquisa, 11 artigos ideais.

Os artigos foram separados e seus autores destacados em uma tabela com ajuda do software Excel. Daí, construiu-se os alicerces para as análises pretendidas. Em um primeiro momento, foram elencados os autores mais produtivos e suas respectivas colaborações. Em seguida, foi construída uma matriz quadrada, simétrica, com os autores e seus citantes, a fim de obter a rede de citação e cocitação desenvolvida no software VOSViewer.

\section{Análise dos dados}

Diante do corpus analisado, foi possível destacar que poucos artigos relacionados à temática foram recuperados na base BRAPCI. É possível visualizar apenas um artigo para os anos de 1993, 2003, 2014 e 2015, três artigos no ano de 2010 e quatro artigos em 2011. Este fato mostra uma presença ainda tímida da $\mathrm{AD}$ em todo universo da CI contemplada pela BRAPCI, em sua maioria utilizada como metodologia de pesquisa.

Uma hipótese para esse fato seria os pesquisadores da CI utilizarem meios de comunicação de outras áreas para a disseminação do conhecimento da $\mathrm{AD}$, como eventos e revistas multidisciplinares, uma vez que a 
AD está intimamente ligada ao campo da Linguística e outras Ciências, as Humanas e Sociais.

Este fato mostra uma presença ainda tímida da AD em todo universo da CI contemplada pela BRAPCI, em sua maioria utilizada como metodologia de pesquisa.

A Figura 1 mostra a rede citante-citado dos autores expoentes e seus referenciais na temática de $\mathrm{AD}$, no período estudado.

Para a construção da rede, foram considerados todos os referentes citados pelo menos por duas vezes em seu total, a fim de eliminar referentes alternativos e obter um resultado mais refinado e sem dispersão, congruente com a temática com a busca da $\mathrm{AD}$ de matriz francesa nos estudos da CI no Brasil. (figura I em apêndice)

De acordo com a rede de citação, observa-se que o autor mais citado foi FOUCAULT, M, o qual apresenta uma frequência de citação absoluta igual a 48. Tal resultado expressa-se, também, devido à busca realizada, uma vez que esta exigia a participação do autor no artigo. Em seguida, tem-se ORLANDI, EP e PECHEUX, M, ambos com uma frequência de citação absoluta de 14, e FROHMANN, B, com um total absoluto de frequência igual a nove.

Entende-se, portanto, que FOUCAULT, M; ORLANDI, EP; PECCHEUX, M e FROHMANN, B são os referentes teóricos mais importantes dos pesquisadores que trabalham com a temática da $\mathrm{AD}$ francesa nos estudos da CI, fato que pode ser justificado uma vez que é observado que nesse universo da $\mathrm{CI}$, a $\mathrm{AD}$ é, em sua maioria, abordada como método de pesquisa e relacionada à análise linguística, temáticas abordadas pelos referentes em seus trabalhos.

Observa-se também que BUSCHMANN, J e GASPAR, NR são os pesquisadores que mais utilizam as obras de FOUCAULT, M em seus artigos, e FREITAS, LS e BUSCHMANN, J são autores que, embora tenham apenas um artigo no período e não realizaram artigo em coautoria, estes compartilham os mesmos referenciais teóricos, como FOUCAULT, M; BUDD, JM; FROHMANN, B; RADFORD, GP e RADFORD, ML, um indicativo de que, na temática trabalhada por ambos, estes são os referentes mainstream.

Ainda, observa-se também alguns referenciais isolados, como SCHRADER, AM o qual é referente compartilhado apenas por VÁLIO, EMB e OLIVEIRA, VFF, e DELEUZE, G, o qual apenas referencia o artigo de ROMÃO, LMS e CRUZ, DVN.

Isto analisado, passa-se agora à análise da rede de cocitação dos autores referentes da temática (Figura II em apêndice).

Observa-se que a maior frequência de cocitação ocorre entre FOUCAULT, M e PÊCHEUX, M, i.e., os dois autores foram citados concomitantemente em oito artigos diferentes; FOUCAULT, M e ORLANDI, EP foram co-citados em seis artigos e FOUCAULT, M foi co-citado em cinco artigos tanto com GASPAR, NR quanto com MALDIDIER, D.

Atenção especial também é dada à triangulação de GASPAR, NR; PÊCHEUX, M e FOUCAULT, M, em que somada com ORLANDI, EP e MALDIDIER, D, mostra que estes referentes foram co-citados, concomitantemente, pelo menos em cinco artigos, i.e., praticamente metade da amostra analisada utiliza tais referentes para embasamento teórico de suas pesquisas.

Observa-se também uma triangulação referente à FOUCAULT, M; ORLANDI, EP e FAIRCLOUGH, N, ainda que embora um pouco menos densa que a triangulação anterior, representa também que estes referentes têm sido utilizados pelos pesquisadores em pesquisas referentes à $\mathrm{AD}$ de matriz francesa publicadas no Brasil.

Nesse sentido, entende-se que FOUCAULT, M; PÊCHEUX, M e ORLANDI, EP são os referentes teóricos mais co-citados em todos os trabalhos realizados pelos pesquisadores expoentes na temática $\mathrm{AD}$ de matriz francesa nos estudos da CI.

\section{Considerações finais}

Esta pesquisa propôs realizar uma análise bibliométrica das comunidades discursivas referentes aos pesquisadores brasileiros expoentes que tratam da temática Análise do Discurso nos estudos da Ciência da Informação no Brasil.

Depois de selecionado o corpus da pesquisa, foram analisados os indicadores de citação e cocitação a fim de identificar os autores mais produtivos, colaboração científica e seus referentes teóricos, entendendo as estruturas em que se articulam os pesquisadores e temática nos estudos da Ciência da Informação.

À guisa de conclusão, entende-se que FOUCAULT, M; PÊCHEUX, M e ORLANDI, EP são os referentes teóricos mais presentes nos artigos relativos à comunidade discursiva da temática $\mathrm{AD}$ nos estudos da $\mathrm{CI}$ no Brasil. Uma hipótese para este fato é a formação discursiva destes autores, uma vez que ORLANDI, EP é a responsável pela disseminação das ideias de PÊUCHEUX, M e FOUCAULT, M no Brasil por meio de suas traduções, corroborando para a divulgação das ideias centrais que permeiam suas obras.

As maiores frequências de cocitação ocorrem entre FOUCAULT, M e PÊCHEUX, $M$ e FOUCAULT, $M$ e ORLANDI, EP, reiterando a importância destes para a temática. Deve-se atentar também à triangulação GASPAR, NR; PÊCHEUX, M e FOUCAULT, M, em que somada com ORLANDI, EP e MALDIDIER, D, consistem referentes cocitados concomitantemente em pelo menos metade da amostra analisada, o que sugere que 
estes são essenciais para embasamento teórico das pesquisas brasileiras na temática.

A análise destes indicadores consistiu instrumento essencial para o entendimento do comportamento cientifico das comunidades discursivas que abordam a matriz francesa da AD nos estudos da CI no Brasil.

Os resultados mostram que os pesquisadores brasileiros utilizam bases histórica e epistemológica coesa por meio da interação de seus referentes dentro do universo de pesquisa da $\mathrm{AD}$.

Considera-se ainda a presença tímida da matriz francesa da $\mathrm{AD}$ no universo da CI contemplada pela BRAP$\mathrm{CI}$, em que seus artigos, em sua maioria, utilizam a temática apenas como metodologia de pesquisa. Propõe-se, futuramente, realizar uma análise discursiva do corpus analisado, abrangendo título, resumo e palavraschave, a fim de entrelaçar mais fortemente as metodologias bibliométrica e de AD, para a obtenção de resultados que possam comprovar a eficácia concomitante de ambas como metodologia de pesquisa.

\section{Notas}

(1) Optou-se por realizar as buscas na base de dados BRAPCI, pois acredita-se que por ser a principal base de dados que reúne em repositório toda a literatura referente à Ciência da Informação no Brasil, ela consegue avaliar a análise do discurso nos estudos em Ciência da Informação no Brasil.

\section{Referências}

Althusser, L. P. (1985) Aparelhos Ideológicos de Estado. 7 ed. Rio de Janeiro: Graal, 1985.

Castanha, R. C. G.; Lima, L. M.; Martínez-Ávila, D. (2017) Análise do discurso sob a perspectiva bibliométrica nos estudos de Ciência da Informação no Brasil. // Perspectivas em Ciência da Informação 22:1 (2017) 17-37.

Finlay, M. (1987). Powermatics: A discursive critique of new communications technology. Routledge, 1987.

Freitas, L. S. (2010). A análise do discurso e o campo informacional: usos atuais e alcance epistemológico: uma atualização. // InCID: Revista de Ciência da Informação e Documentação 1:1 (2010) 32-55.

Foucault, M. (1986) A arqueologia do saber. Rio de Janeiro: Forense, 1986.

Frohmann, B. (1994) Discourse analysis as a research method in library and information science. // Library \& Information Science Research 16: 1 (1994) 119-138.

Guimarães, E. (2001). Expressão modalizadora no discurso de divulgação científica. // Educação e Linguagem, 4:5 (2001) 65-77.

Grácio, M. C. C.; Oliveira, E. F. T. (2013) Análise de cocitação de autores: um estudo teórico-metodológico dos indicadores de proximidade, aplicados ao GT7 da ANCIB. // Liinc em Revista 9:1 (2013) 196-213.
Gregolin, M. R. V. 1995. A Análise do Discurso: Conceitos e aplicações. // Alfa: Revista de Linguística. São Paulo 39:1 (1995) 13-21.

Henry, P. (1997). Os fundamentos teóricos da "análise automática do discurso" de Michel Pêcheux (1969). // Gadet, F.; Hak, T. (orgs.). Por uma análise automática do discurso: uma introdução à obra de Michel Pêcheux. 3ed. Campinas: Editora da UNICAMP, 1997. 13-38.

Lima, L. M.; Moraes, J. B. E.; Martínez-Ávila, D. (2015) A genealogia do conceito de Ciência da Informação no Brasil: Uma análise discursiva a partir de periódicos fundacionais na área. // José Augusto Chaves Guimarães; Vera Dodebei. (Org.). Organização do Conhecimento e Diversidade Cultural. Marília: ISKO-Brasil; FUNDEPE, 2015. 210-218.

Mazière, F. (2007) A análise do discurso: história e práticas. São Paulo: Parábola editor, 2007.

Maingueneau, D. (1997). Novas tendências em análise do discurso. Campinas: Pontes,1997.

Miguel, S.; Moya-Anégon, F.; Herrero-Solana, V. (2007) El análisis de co-citas como método de investigación en Bibliotecología y Ciencia de la Información. // Investigación bibliotecológica 21:43 (2007) 39-155.

Orlandi. E. P. (2003) análise do discurso: princípios e procedimentos. 5ed. Campinas, SP: Pontes, 2003. p.37.

Saussure, F. (1973) Curso de linguística geral. 5. ed. São Paulo: Cultrix, 1973.

Silva, A. R.; Baptista, D. M. (2015) Abordagens de Análise de Discurso na Ciência da Informação: panorama dos estudos brasileiros. // Informação \& Sociedade: Estudos 25:2 (2015) 89-103.

Small, H. (2004) On the shoulders of Robert Merton: Towards a normative theory of citation. // Scientometrics, 60:1 (2004) 71-79.

Vanz, S. A. S.; Caregnato, S. E. (2003) Estudos de citação: uma ferramenta para entender a comunicação científica. // Em questão: Revista da Faculdade de Biblioteconomia e Comunicação da UFRGS, Porto Alegre 9:2 (2003) 295307.

Copyright: () 2017. Castanha e Lima. This is an openaccess article distributed under the terms of the Creative Commons CC Attribution-ShareAlike (CC BYSA), which permits use, distribution, and reproduction in any medium, under the identical terms, and provided the original author and source are credited.

Received:2017-08-12/ Accepted: 2017-11-03 


\section{Appendix}

Figura I

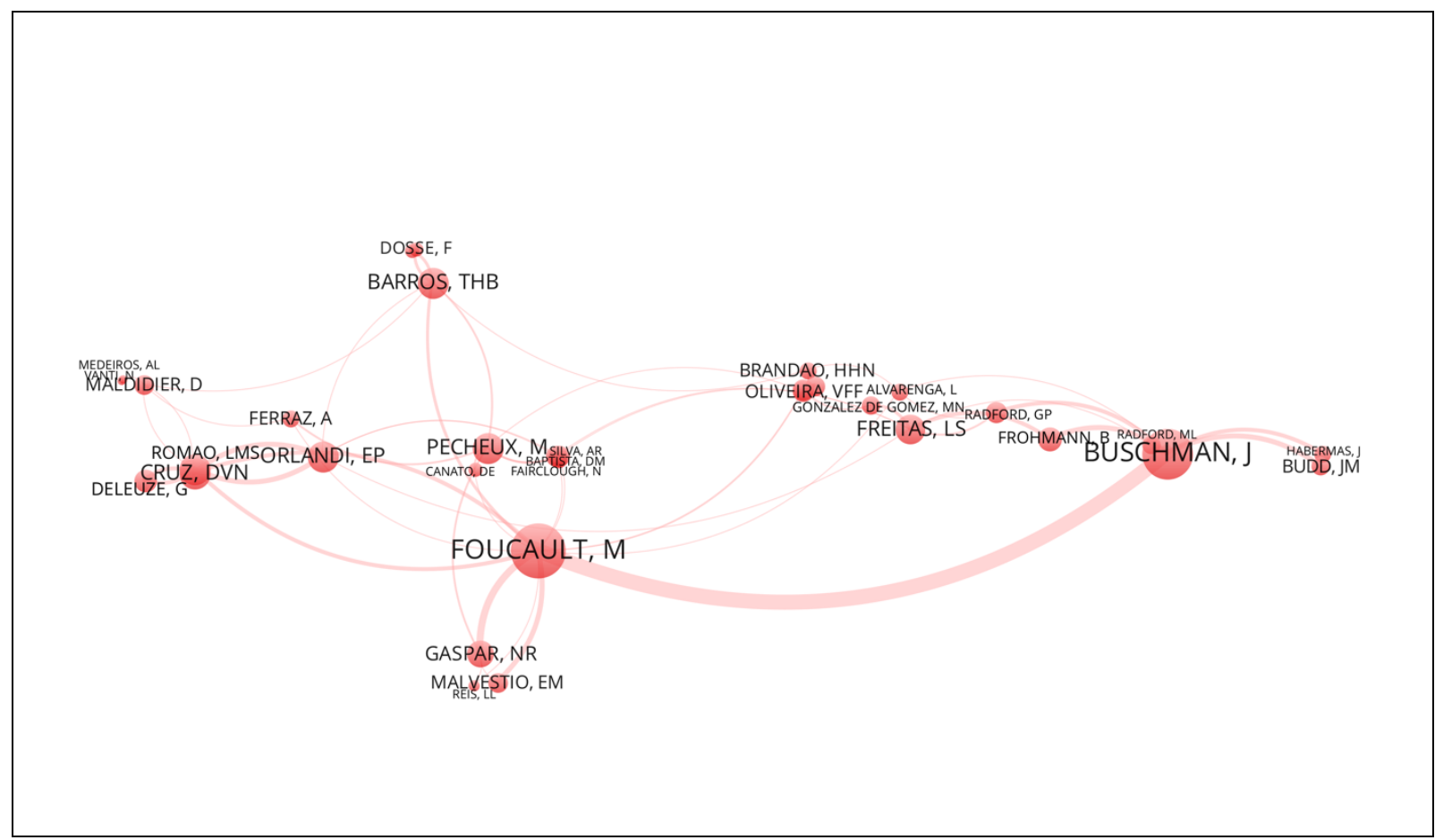

Figura I. Rede citante-citado dos referentes dos pesquisadores de AD em CI no Brasil (1972-2015). Fonte: Elaborado pelas próprias autoras.

Figura II

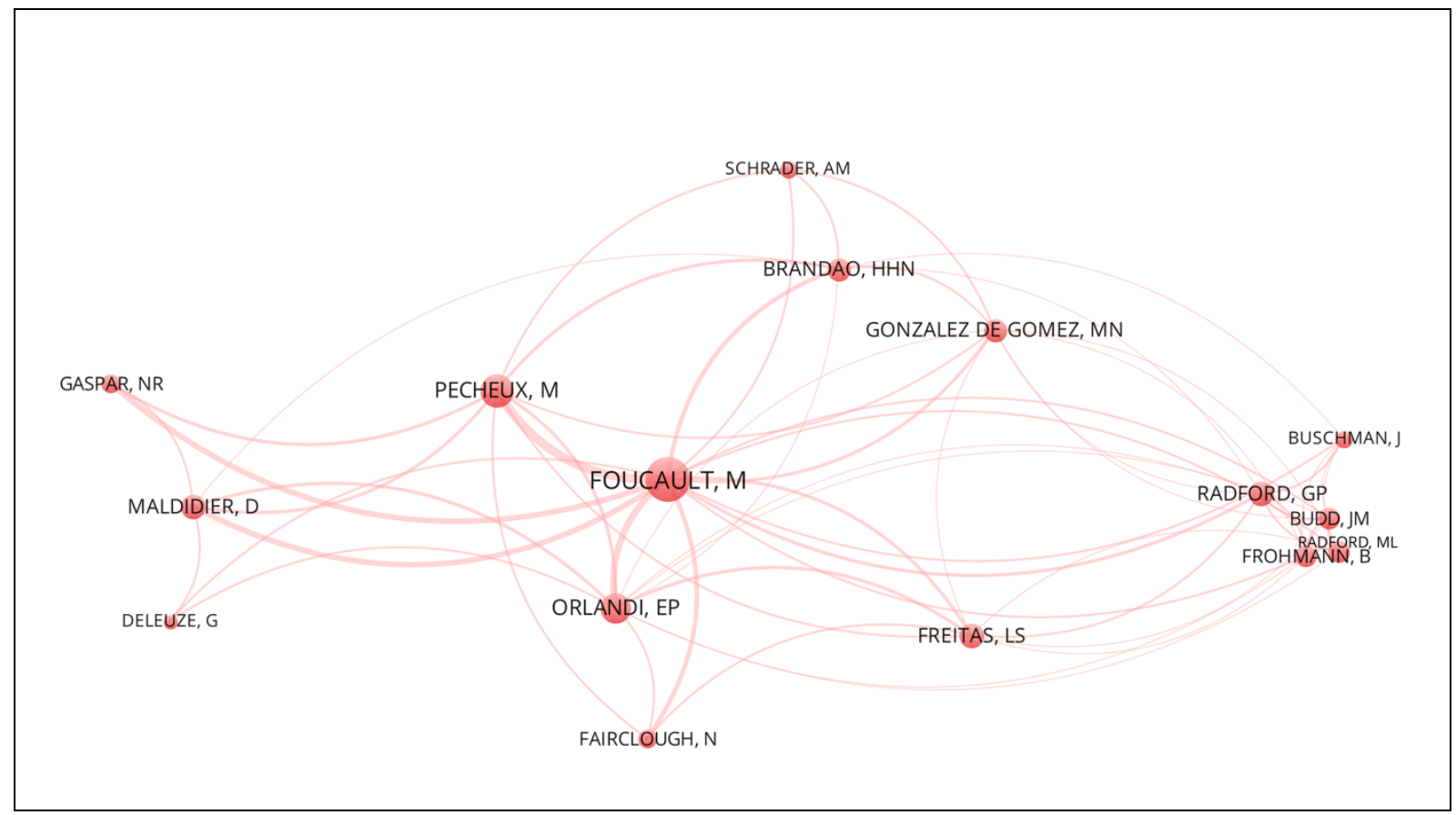

Figura II. Rede de cocitação entre os referentes mais citados dos pesquisadores de AD em CI no Brasil (1972-2015). Fonte: Elaborado pelas próprias autoras.

Castanha, Renata Cristina Gutierres; Lima, Larissa de Mello. Estudo das comunidades discursivas formadas pela interdisciplinaridade entre as áreas de Ciência da Informação e Análise do Discurso. // Brazilian Journal of Information Studies: Research Trends. 12:1 (2018) p.61-67 ISSN 1981-1640. 